\title{
ACUTE NONCARDIOGENIC PULMONARY EDEMA FOLLOWING NEOSTIGMINE ADMINISTRATION IN THE ENDOTRACHEAL INTUBATION STATE AFTER TONSILLECTOMY
}

\author{
WOO JIN CHO ${ }^{1}$, SO HUI YUN ${ }^{1,2 *}$, SEUNG EUN SONG ${ }^{1}$, CHANGROCK KNA ${ }^{1}$, SURAN YU ${ }^{1}$
}

${ }^{1}$ Department of Anesthesiology and Pain Medicine, Jeju National University Hospital, Jeju City, Republic of Korea. ${ }^{2}$ Department of Anesthesiology and Pain Medicine, Jeju National University School of Medicine, Republic of Korea. Email: juguyam@gmail.com

Received: 15 February 2021, Revised and Accepted: 31 March 2021

\section{ABSTRACT}

Acute pulmonary edema during the perioperative period can have various causes. A 20-year-old woman was admitted for tonsillectomy and adenoidectomy. She had nasal congestion for 2 months, chronic sinusitis with polyps, and diffuse lymphoid hyperplasia. A biopsy and peripheral blood smear were performed to rule out a lymphoma before surgery. We injected neostigmine $1.5 \mathrm{mg}$ and glycopyrrolate $0.4 \mathrm{mg}$ at the end of the surgery. Two minutes later, the secretion and peak airway pressure increased as well as the $\mathrm{CO}_{2}$ levels. The patient remained sedated and suctioning continued for approximately 20 min before extubation. The secretions reduced and there was an improvement in clinical symptoms as the pinkish foamy pattern became whitish. Presumed treatment of neostigmine hypersensitivity or surgery can be used to resolve perioperative chronic partial airway obstruction.

Keywords: Drug hypersensitivity, General anesthesia, Neostigmine, Pulmonary edema, Tonsillectomy.

(C) 2021 The Authors. Published by Innovare Academic Sciences Pvt Ltd. This is an open access article under the CC BY license (http://creativecommons. org/licenses/by/4.0/) DOI: http://dx.doi.org/10.22159/ijms.2021v9i3.41120. Journal homepage: https://innovareacademics.in/journals/index.php/ijms

\section{INTRODUCTION}

Acute pulmonary edema during the perioperative period can have various causes. During surgery, negative pulmonary edema pressure often presents as airway obstruction after extubation. However, pulmonary edema may occur before extubation in some rare cases. Neostigmine might induce noncardiac pulmonary edema by impairing upper airway function by dilating muscles and causing the upper airway to narrow [1,2]. In this case, pulmonary edema occurred perioperatively, as such, neostigmine hypersensitivity was suspected.

\section{CASE REPORT}

A 20-year-old female with a weight of $61.6 \mathrm{~kg}$ was admitted for tonsillectomy and adenoidectomy. She had visited the hospital about 2 months ago for severe nasal congestion and was admitted for the surgical removal of nasal polyps. From her past medical history, she had no specific drug allergy. Physical examination revealed diffused lymphoid follicular hyperplasia in the nasopharynx and base of the tongue, chronic sinusitis, and a polypoid mass with nasal polyps. Computed tomography of the paranasal sinuses showed diffused lymphoid tissues hyperplasia in the palatine and lingual tonsil, adenoid in the nasopharynx, and innumerable enlarged lymph nodes in the retropharyngeal and bilateral cervical nodal stations. A biopsy of the suspected site was performed to rule out lymphoma. The patient reported aperiodic history of nocturnal fever but no recent weight loss. The pathologic findings were hyperplasia of the lymphoma. There were no special findings in the peripheral blood smear. Hence, surgery was planned despite the lingual tonsillar hypertrophy. However, at the time of admission, tonsillitis was associated with cold; the patient complained of a blocked ear and stuffy nose without dyspnea.

On the day of the surgery, anesthesia was induced using thiopental $300 \mathrm{mg}$, rocuronium $50 \mathrm{mg}$, and lidocaine $50 \mathrm{mg}$ without premedication. After the spontaneous breathing disappeared, there was no problem with the mask ventilation. The GlideScope video laryngoscope (Verathon Medical Inc., Canada) was used for intubation because the dimensions of the mass were unclear and the tracheal orifice was hard to locate due to the agglomeration of hyperplastic lymphoid tissues from the base of the tongue. Since the vocal cord was covered by the mass and could not be seen clearly, the first successful attempt was only achieved by blind intubation. The ventilator was maintained at a peak pressure of $18 \sim 20 \mathrm{mmHg}$ at tidal volume $500 \mathrm{ml}$ and a frequency of 12 times/min in volume-controlled mode by sevoflurane administration. The total operation time was 92 min. Neostigmine $1.5 \mathrm{mg}$ and glycopyrrolate $0.4 \mathrm{mg}$ were then injected as reversal agents for the neuromuscular blocker. Immediately after the administration of the reversal agents, secretions gradually increased, and an upper truncal rash was observed. After 2-3 min of drug administration, the secretion pattern changed from whitish to pink and frothy. In the left upper lung field, there were prominent crackle sounds and the peak pressure increased to $25-30 \mathrm{mmHg}$ and the $\mathrm{EtCO}_{2}$ up to $50 \mathrm{mmHg}$. Massive suction continued under deep sedation by increasing the inhalation gas and intensive care unit care was arranged in case the test results demanded it. However, the secretions gradually decreased and the clinical symptoms improved. Approximately $20 \mathrm{~min}$ after the patient's symptoms developed, a chest X-ray was taken in the operating room (Fig. 1). The X-ray showed an increase in peribronchial infiltration in the left lung field; however, the pulmonary edema was not as severe as expected, and the symptoms improved. Arterial blood gas analysis (ABGA) was performed to confirm the actual degree of gas exchange. ABGA before extubation revealed a $\mathrm{pH}$ of $7.385, \mathrm{pCO}_{2} 42.2 \mathrm{mmHg}, \mathrm{pO}_{2}$ $556 \mathrm{mmHg}$, and actual base excess $0.1 \mathrm{mmol} / \mathrm{L}$. The ventilator setting was maintained at a peak pressure of $20 \mathrm{mmHg}$, tidal volume $500 \mathrm{ml}$, and a frequency of 15 times/min. After extubation without additional reversal agents, monitoring under oxygen supply was continued in the general ward, and anesthesia was terminated with a total anesthesia time of $152 \mathrm{~min}$. The intraoperative fluid was administered with 200 $\mathrm{ml}$ of Hartmann solution, and the estimated blood loss was $20 \mathrm{ml}$. The patient complained of mild chest discomfort until 1 day after surgery; however, the symptoms improved thereafter.

\section{DISCUSSION}

This article reports the case of a patient with pulmonary edema that suddenly occurred following the administration of neostigmine before extubation after tonsillectomy surgery. Although the symptoms improved spontaneously, the etiology needs to be investigated. 


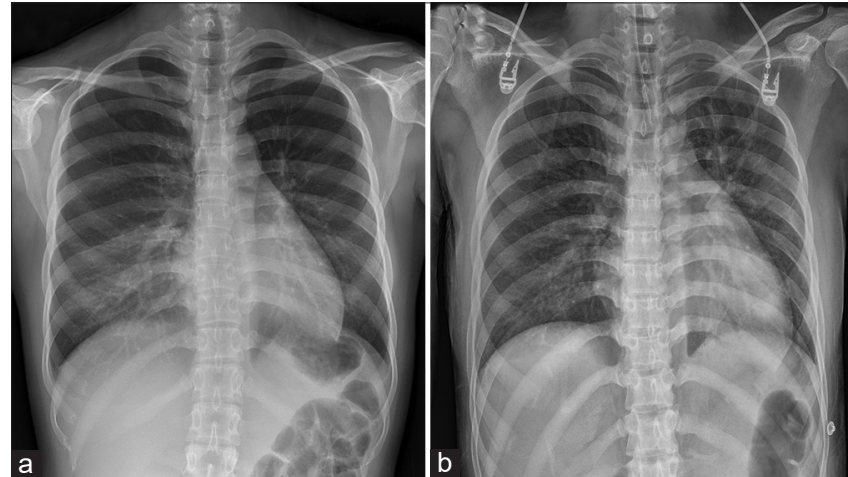

Fig. 1: Chest X-ray findings. (a) No active lung lesion was seen in the pre-operative evaluation, (b) chest X-ray in the operating room showed peribronchial infiltration in the left lung field

Pulmonary edema may be of cardiogenic or neurogenic origin. Other common perioperative causes are fluid overload or drug reaction. In our patient, the intraoperative fluid infusion was only $200 \mathrm{ml}$, and there was no underlying heart disease, such as left heart failure, which could increase pulmonary pressure. Therefore, in this case, there were two possible causes of noncardiogenic pulmonary edema.

The first is hypersensitivity response to drugs. Neostigmine hypersensitivity reaction could be suspected as the cause. The pathogenesis of drug-induced pulmonary edema is multifactorial and not completely understood and may involve cytotoxicity of lung epithelial cells. The use of neostigmine is known to be safe and effective. However, several cases of acute pulmonary edema due to the use of neostigmine have been reported [1,2]. Neostigmine-induced pulmonary edema was diagnosed based on the symptoms that occurred soon after the administration of neostigmine, while other causes were ruled out. Impaired function of the upper airway dilating muscles caused the narrowing of the upper airway and this might be related to anaphylaxis. Furthermore, the excessive excitation of the sympathetic nervous system is associated with pulmonary edema. In our patient, symptoms and the skin rash on the upper truncal area developed immediately after injecting the drug; based on this, drug hypersensitivity was suspected.

The second is type II NPPE, which is caused by the recovery of spontaneous breathing and strong negative intrathoracic pressure made by forceful inspiratory effort [3]. The patient was young, complained of nocturnal fever, and had hyperplastic lymphoid changes throughout the palatine and lingual tonsils as well as the nasal cavity. It was initially required to rule out lymphoma. Lymphoma is suspected when there is an abnormal increase in lymphocytes in peripheral blood cell cytology. Platelet count and/or white blood cell count are low in anemia The patient's blood test results did not reveal any specific findings, and lymphoma was excluded after biopsy. As compared with that during the outpatient visit, hyperplastic changes were aggravated, and the airway was insufficient for intubation at the time of admission; however, it could be due to cold. This change may have caused the partial airway obstruction preoperatively. Although the patient had a large airway mass before surgery, there was no respiratory distress and no difficulty in mask ventilation during the induction of anesthesia. Nevertheless, this could occur as a result of the perioperative partial airway obstruction relief in young and healthy women due to the temporary generation of strong forces (negative pressure above $30 \mathrm{mmHg}$ ).

Negative pressure pulmonary edema (NPPE) occurs in 1 out of 1,000 patients under anesthesia [4]. It usually occurs during initial airway management or after extubation [4-6]. The incidence of perioperative NPPE is generally associated with acute upper airway obstruction or postoperative residual curarization effects. It is rarely reported in an intubated state [1]. NPPE can be divided into two types depending on the mechanism of occurrence [7]. Type I is associated with forceful inspiratory effort due to acute airway obstruction. Residual postoperative curarization is associated with reduced pharyngeal muscle tone and possible upper airway obstruction [8]. Therefore, in the intubated state, association with type I is rare. Type II occurs more often after chronic partial obstruction of the upper airway has been resolved. It is predicted to occur after adenoidectomy/tonsillectomy, laryngeal mass resection, or reduction of a hypertrophic redundant uvula [7].

According to previous studies, symptoms and clinical signs of pulmonary edema resolves rapidly [9]. Although many patients with acute noncardiogenic pulmonary edema have been reported to recover with conservative management, some patients require temporary intubation and mechanical ventilation. This case showed rapid recovery and stabilization

\section{CONCLUSION}

Even if the airway is secured through intubation, acute noncardiogenic pulmonary edema must be recognized and managed according to the patient's symptoms.

\section{CONFLICTS OF INTEREST}

No potential conflicts of interest relevant to this article were reported.

\section{FUNDING/SUPPORT}

Not applicable.

\section{FINANCIAL DISCLOSURE}

The study was performed according to the Helsinki Declaration and approved by the Institutional Review Board (IRB no. 2020-02-006)

\section{REFERENCES}

1. Zhang W, Ning C, Zhao G, Su Z. Acute noncardiogenic pulmonary edema after neostigmine administration during the recovery period of general anesthesia: Acase report. Medicine (Baltimore) 2018;97:e10525.

2. Raiger LK, Naithani U, Vijay BS, Gupta P, Bhargava V. Noncardiogenic pulmonary oedema after neostigmine given for reversal: A report of two cases. Indian J Anaesth 2010;54:338-41.

3. Bhattacharya M, Kallet RH, Ware LB, Matthay MA. Negative-pressure pulmonary edema. Chest 2016;150:927-33.

4. Krodel DJ, Bittner EA, Abdulnour R, Brown R, Eikermann M. Case scenario: Acute postoperative negative pressure pulmonary edema. Anesthesiology 2010;113:200-7.

5. Jo YY, Kim KH, Kil HK. Negative pressure pulmonary edema related to bronchospasm during anesthetic recovery. Korean J Anesthesiol 2013;65:91-2.

6. Liu R, Wang J, Zhao G, Su Z. Negative pressure pulmonary edema after general anesthesia: A case report and literature review. Medicine (Baltimore) 2019;98:e15389.

7. Udeshi A, Cantie SM, Pierre E. Postobstructive pulmonary edema. J Crit Care 2010;25:508.e1-5.

8. Eikermann M, Vogt FM, Herbstreit F, Vahid-Dastgerdi M, Zenge MO, Ochterbeck C, et al. The predisposition to inspiratory upper airway collapse during partial neuromuscular blockade. Am J Respir Crit Care Med 2007;175:9-15.

9. Koh MS, Hsu AA, Eng P. Negative pressure pulmonary oedema in the medical intensive care unit. Intensive Care Med 2003;29:1601-4. 